\title{
Epigenetic Remodeling of Delta FosB Protein: Its Role in Regulation of Stress
}

\section{Gunjan Dhawan, Indra Mani and Kavita Vasdev* \\ Department of Microbiology, Gargi College, (University of Delhi), India}

*Corresponding author: Kavita Vasdev, Associate Professor, Department of Microbiology, Gargi College, (University of Delhi), Siri Fort Road, New Delhi-110049, India, Tel: +91-9811873144; Email: atvikav@gmail.com

\section{Research Article}

Volume 3 Issue 1

Received Date: April 09, 2018

Published Date: April 27, 2018

DOI: $10.23880 /$ cclsj-16000121

\section{Abstract}

Stress is not affected only on brain but also on the other parts of body like changes in heart rate, blood pressure levels, circadian rhythm etc. Recent studies have been established that exposure to stress promotes alterations in several epigenetic characters like histone acetylation and methylation as well as DNA methylation, in various limbic brain regions. Chromatin remodeling processes are necessary for learning and memory. However, abnormal epigenetic modifications can lead to cognitive deficits. DeltaFosB $(\Delta \mathrm{FosB})$ is protein of Fos family. FosB gene forms FosB and $\Delta$ FosB as product. Increased expression of FosB over $\triangle$ FosB in nucleus accumbens (NAc) region of brain protects animals from the deleterious effects of chronic stress. Moreover, epigenetically, H3K9me2 is enriched at the FosB promoter in NAc of human depressed patients. FosB has very low life while $\Delta$ FosB has exceptionally long life span. Thus persists for long time in the stress condition and leads to depression and anxiety. It has also been revealed that elevation in $\Delta$ FosB level occurs due to chronic stress condition. The epigenetic factors responsible for stress are governed by $\Delta$ FosB expression level. The expression of $\Delta$ FosB in turn depends on the presence of serum response factor (SRF) transcription factor. SRF transcription factor is encoded by srf gene. To understand the mechanism of stress condition, srf gene can be one of the promising targets to uncover the problems related to stress conditions.

Keywords: Stress; Epigenetic; $\Delta$ Fosb; Srf Gene; Fosb; Chromatin Remodeling

Abbreviations: SRF: Serum Response Factor; Nac: Nucleus Accumbens; PTSD: Post-Traumatic Stress Disorder; HPA: Hypothalamic-Pituitary-Adrenal; BDNF: Brain Derived Neurotrophic Factor; TPA: Tissue Plasminogen Activator; CRF: Corticotrophin Releasing Factor; Ecb: Endocannabinoids; FAAH: Fatty Acid Aminohydrolase; GR: Glucocorticoid Receptor; ERK: Extracellular Signal-Regulated Kinase; MAPK: Mitogen-
Activated Protein Kinase; HDAC: Histone Deacetylase; AD: Alzheimer's disease; HMTs: Histone Methyltransferases; SAM: S-adenosylmethionine.

\section{Introduction}

Stress is not always what it seems to be. Stress can be divided into three categories: good stress; tolerable stress 


\section{Cell \& Cellular Life Sciences Journal}

and toxic stress. Early life stress can alter neural architecture thus can lead to toxic stress, development of psychopathologies such as post-traumatic stress disorder and depression $[1,2]$. There is a strong inter-individual variability in susceptibility to stress. Most of the individuals remain resilient: they can maintain normal physiological and psychological functions despite being subjected to horrendous stress [3,4]. Stress does not occur due to any single reason. A lot of factors are responsible for the stress condition. It can be genetic or epigenetic factors. In this increasing technological world, the standard of living of a person defines its mental and social health along with the physical health. Increasing work pressure adversely affects the health condition and leading cause of stress in humans.

Chronic stress refers to intense traumatic events like accidents, physical assault, sexual assault, natural disasters, or combat exposure, leading to psychopathologies such as complex post-traumatic stress disorder (PTSD) or non-traumatic but major events in life, whereby an individual is exposed to sustained periods of stress, for example, care giving, difficult divorce, or a stressful work environment leading to burnout [2].

The brain is the central organ for processing and adapting to various social and physical stresses, as it is the organ that stores memories, regulate physiological and behavioral responses and determines what is threatening for the body [5]. The thought of a stressful situation activates many neuronal circuits, particularly hypothalamic-pituitary-adrenal axis (HPA axis), the locus coeruleus and autonomic noradrenergic centers in the brain stem $[6,7]$.

Various mediators that help to adapt to stress include: cell surface mediators, cytoskeletal mediators, epigenetic regulation and non-genomic mechanisms [8]. Exposures to multiple stressors and dysregulation of the non-linear interactions lead to wear and tear of the body and the brain. This is termed as allostatic load and overload [5,9]. Allostasis is the active process of adapting to stressors via mediators such as cortisol and autonomic, metabolic and immune system that act together in a non-linear fashion to maintain homeostasis [10].

The effect of stress is not only on brain but also on the other body parts like changes in heart rate, blood pressure levels, circadian rhythm etc. Chromatin remodeling processes are necessary for learning and memory. Abnormal epigenetic modifications can lead to cognitive deficits. Moreover, it has been observed in various studies that exposure to stress promotes alterations in various epigenetic marks; in particular, histone acetylation and methylation as well as DNA methylation, in various limbic brain regions.

\section{There are Some Molecules that are Necessary/Permissive for Remodeling}

a) Brain derived neurotrophic factor (BDNF): It is a facilitator of plasticity and growth. BDNF overexpression blocks effects of chronic stress. BDNF haplo insufficiency prevents stress induced plasticity $[11,12]$.

b) Tissue plasminogen activator (tPA): It is a secreted signaling molecule and protease. It is required for stress-induced spine loss in hippocampus and medial amygdala. It is required for acute stress-induced increase in anxiety. Corticotrophin releasing factor (CRF) is responsible for activating tPA. CRF in amygdala regulates tPA release $[13,14]$.

c) Corticotrophin releasing factor (CRF): It is secreted in hippocampus by interneurons. It downregulates thin spines via RhoA signaling $[14,15]$.

d) Lipocalin-2: It gets activated at the time of acute stress. It downregulates mushroom spines. Lipocalin-2 KO increases neuronal excitability and anxiety $[16,17]$.

e) Endocannabinoids (eCB): It gets induced via glucocorticoids. It regulates emotionality and HPA habituation and shut off.

CB1 receptor KO increases anxiety and basolateral amygdala dendrite length and causes stress like retraction of prefrontal cortical dendrites, likely through the regulation of glutamateric transmission.

Fatty acid aminohydrolase (FAAH) is a key regulator of eCB action [18-20].

\section{Stressors Alter Gene Expression Via Following Mechanisms}

a) Direct effect of glucocorticoids on gene transcription

b) Activation of epigenetic mechanisms involving histone modification and methylation/hydroxyl-methylation of CpG residues in DNA [21,22].

\section{Epigenetic Mechanism behind the Stress Condition}

Many genes that get altered after glucocorticoid and chronic stress exposure in the hippocampus are known as epigenetic regulators [23]. For example; social defeat stress in rodents showed changes in both histone 


\section{Cell \& Cellular Life Sciences Journal}

methylation and acetylation. The mechanism underlying this includes: Glucocorticoid, via glucocorticoid receptor (GR), facilitates signaling of extracellular signal-regulated kinase (ERK)-mitogen-activated protein kinase (MAPK) (ERK-MAPK) pathway to downstream mitogen and stressactivated protein kinase-1(MSK-1) and ElK-1.The activation of this pathway results in serine $10(\mathrm{~S} 10)$ phosphorylation and lysine 14(K14) acetylation at histone H3 i.e.H3S10p-K14ac. This leads to induction of immediate early genes, c-Fos and Erg-1 [24,25]. Epigenetically, H3K9me2 is enriched at the FosB promoter in NAc of human depressed patients. Expression of a construct containing a transcriptionally repressive domain (Fosb-ZFP-G9a) decreased FosB expression and increased the level of the repressive histone modification H3K9me2 [26]. It has also shown that expression of Fosb-ZFP-G9a increased depressionlike behavior in a chronic social defeat stress model, indicating that the $\mathrm{H} 3 \mathrm{~K} 9 \mathrm{me} 2$ modification mediates this effect [26]. Increased expression of FosB over $\Delta$ FosB in nucleus accumbens region of brain protects animals from the deleterious effects of chronic stress [26].

Vialou, et al. have used bitransgenic mice that inducibly overexpress $\triangle F$ FosB specifically in the adult NAc and dorsal striatum to test the functional consequences of $\Delta$ FosB induction. These mice have shown a reduced propensity to develop social avoidance after four or ten days of social defeat (Figure 1) [27].

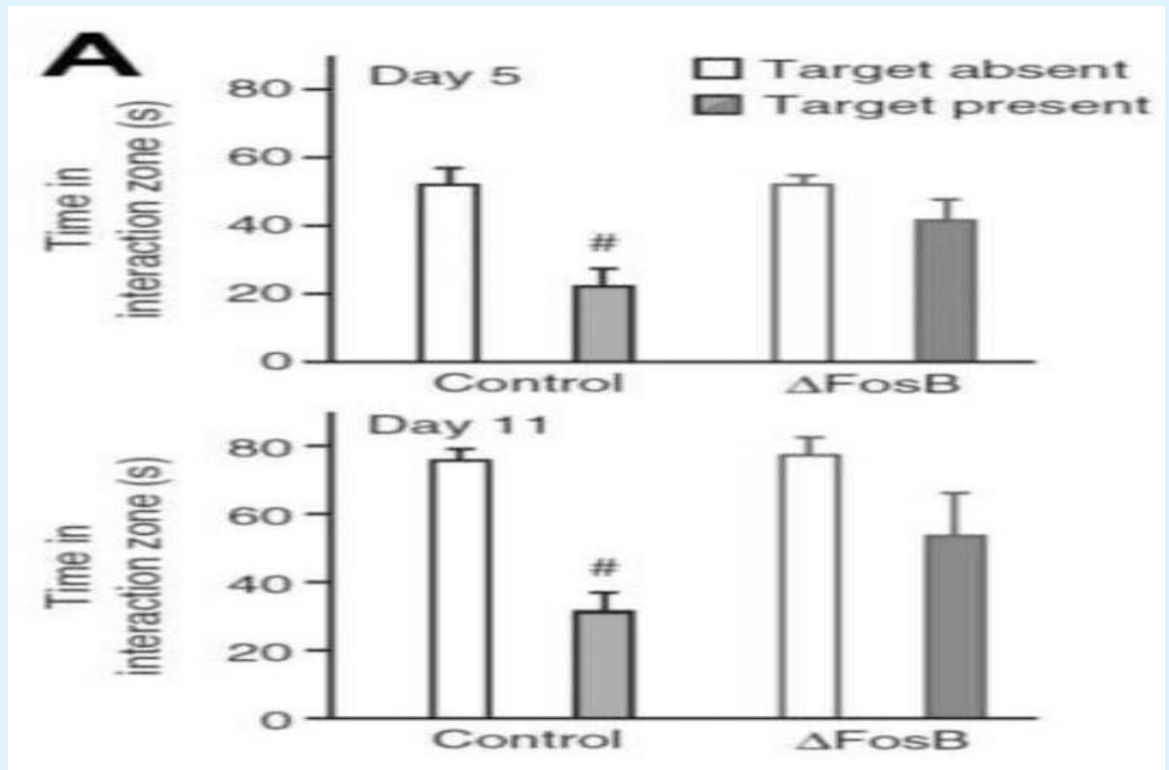

Figure 1: $\triangle$ FosB induction in nucleus accumbens (NAc) region by chronic social defeat stress mediates resilence. Inducible bitransgenic mice over expressing $\triangle \mathrm{FosB}$ in D1type MSNs do not develop the social aversion, which is a hallmark of social defeat stress after either 4or 10days of defeat with mice tested on days 5 or 11, respectively [27].

Corbett, et al. demonstrated that spontaneous seizures increase expression of $\Delta \mathrm{FosB}$, a highly stable Fos-family transcription factor, in the hippocampus of an Alzheimer's disease (AD) mouse model [28]. $\Delta$ FosB suppressed expression of the immediate early gene c-Fos, which is critical for plasticity and cognition, by binding its promoter and triggering histone deacetylation. Acute histone deacetylase (HDAC) inhibition or inhibition of $\triangle$ FosB activity restored c-Fos induction and improved cognition in AD mice. Administration of seizure inducing agents to nontransgenic mice also resulted in $\Delta$ FosB- mediated suppression of c-Fos, suggesting that this mechanism is not confined to AD mice. These results explain observations that c-Fos expression increases after acute neuronal activity but decreases with chronic activity.

The Fos family proteins heterodimerize with Jun family proteins (c-Jun, JunB or JunD) to form active activator protein-1 (AP-1) transcription factors that bind to AP-1 sites, which is present in the promoters of certain genes to regulate their transcription. These Fos family proteins 


\section{Cell \& Cellular Life Sciences Journal}

are induced rapidly and transiently in specific brain regions after acute administration of many drugs of abuse
[29]. Very different responses have been observed after chronic administration of drugs of abuse (Figure 2).

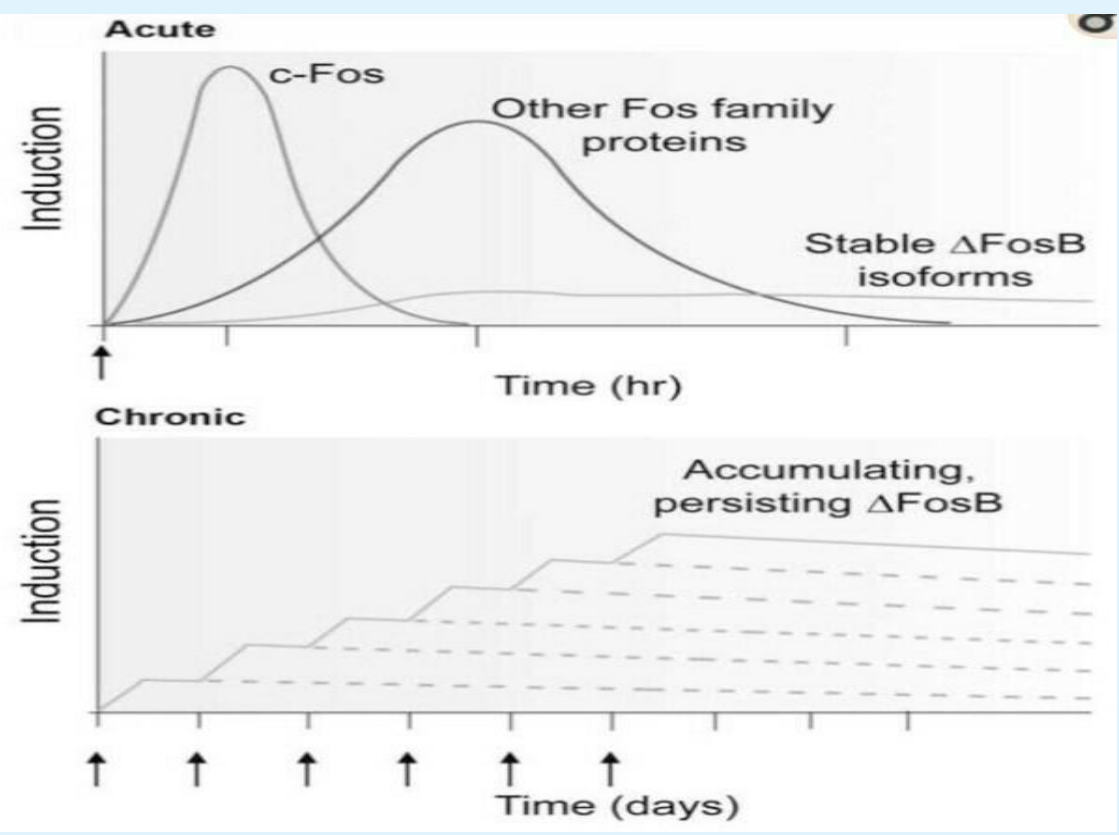

Figure 2: Scheme showing the gradual accumulation of $\Delta$ FosB versus the rapid and transient induction of other Fos family proteins in response to stress or another stimulus [29].

FosB gene forms FosB and $\triangle \mathrm{FosB}$ as product. $\triangle \mathrm{FosB}$ is protein of Fos family. These FosB have very low life while $\Delta$ FosB has exceptionally long life span. Thus persist for long time in the stress condition and leads to depression and anxiety.

Two mechanisms are responsible for the stability of $\triangle \mathrm{FosB}$ :

a) $\triangle F$ osB has a deletion of 2degron domains at the $C$ terminal as compared to FosB. One of the domain targets FosB for ubiquitylation and degradation in proteosome and the other targets FosB degradation by an ubiquitin and proteasome independent manner (Figure 3).

b) $\triangle \mathrm{FosB}$ is phosphorylated by several protein kinases at its N-terminal, which stabilizes the protein.

Earlier it was noticed that $\Delta$ FosB gets activated due to alcohol consumption but the mechanism was not clear. Pauli, et al. [30] identified different patterns of FosB/DeltaFosB expression during withdrawal between
EtOH_High and EtOH_Low groups [30]. They also showed that behavioral variability observed in acquisition phase of ethanol induced locomotor sensitization is accompanied by distinct neuronal plasticity during withdrawal period. In addition, their results suggested that different patterns of FosB/Delta FosB expression detected in sensitized and non-sensitized mice were more related to withdrawal period rather than to the chronic drug exposure, probably due to the tolerance of druginduced FosB/DeltaFosB transcription.

It has also been discovered that elevation in $\Delta \mathrm{FosB}$ level occurs due to chronic stress condition. Decreasing the expression of $\Delta$ FosB or increasing the level of FosB can help in relieving from stress. $\Delta$ FosB is produced due to activation of serum response factor (SRF) that is coded by the gene Srf gene.

$\Delta \mathrm{FosB}$ is unique in that it accumulates in response to repeated stimulation due to its unusual protein stability [31]. 


\section{Cell \& Cellular Life Sciences Journal}

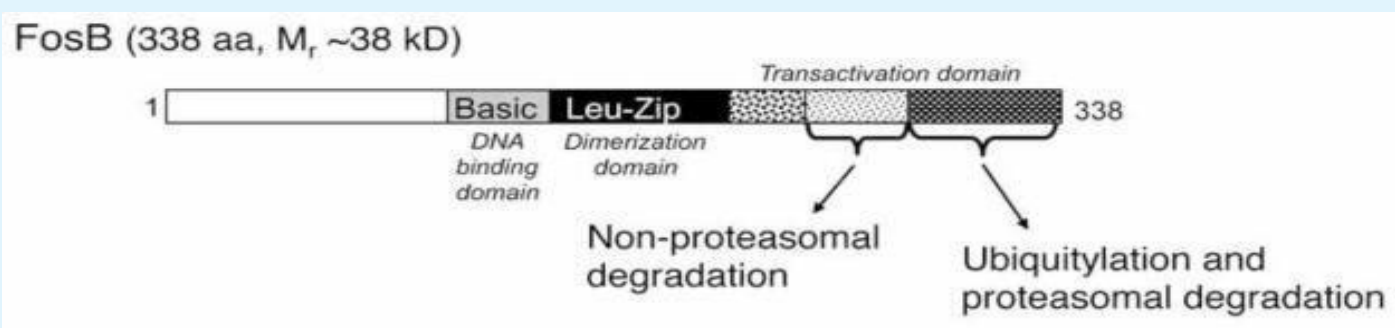

$\triangle \mathrm{FosB}\left(237 \mathrm{aa}, \mathrm{M}_{\mathrm{r}} \sim 26 \mathrm{kD}\right)$

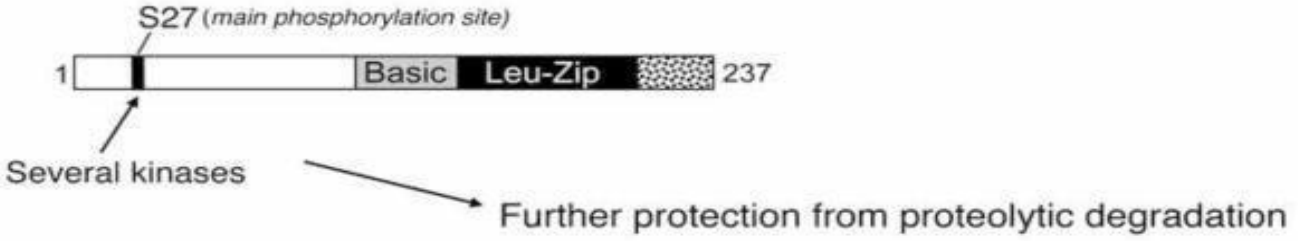

Figure 3: Biochemical basis of $\Delta$ FosB's unique stability. $\Delta$ FosB is formed by deletion of some portion of FosB as shown in the figure, which provides the unique stability to $\Delta \mathrm{FosB}[29]$.

\section{Epigenetics}

Epigenetics is the mechanism that regulates genomic information by chemical modifications to DNA and histones that can alter cell and tissue specific patterns of gene expression [32,2]. These reversible modifications of DNA and chromatin structure mediate the interaction of the genome with a variety of environmental factors and generate changes in the pattern of gene expression in response to these factors [32]. An epigenetic trait is a stable, mitotically and meiotically heritable phenotype that results from changes in the pattern of gene expression without alterations of the DNA sequence [32].

\section{Epigenetic mechanisms}

\section{A. DNA Methylation:}

Methylation of cytosine residue at 5'position results in projection of methyl group into the major groove ofDNA [33]. In mammals, this predominantly occurs in the palindromic sequence 5'-CpG-3'. The location of $\mathrm{CpG}$ bases in mammalian DNA occurs at high concentration in some specific regions called CpG islands.

CpG methylation in promoter region generally represses transcription of genes.DNA methylation is catalysed by DNA methyltransferases (DNMTs) [34]. DNMTs can directly interact with transcription factors, performing the methylation of promoter region at specific locations. Nearly 80 transcription factors are found to be associated with DNMTs [35].

\section{B. Histone Modifications:}

In case of eukaryotes DNA is packed densely into chromatin through interactions with large protein complexes, nucleosomes. Nucleosome core is composed of histone octamer. The N-terminal tails of histones exhibit multiple, reversible covalent modifications. These alter the accessibility of DNA to the transcriptional machinery in a regulated fashion [36].

a) Acetylation: Histone acetylation (Figure 4) negates positive charge of lysine residue in histone tail. It is associated with transcriptional activation [37,38]. Histones are acetylated by histone acetyltransferases (HATs). HATs use acetyl coenzyme A as a cosubstrate. Deacetylation occurs by histone deacetylases (HDACs). HATs acetylate multiple lysine residues in the tails of both $\mathrm{H} 3$ and $\mathrm{H} 4$ [36].

b) Methylation: Histone methylation (Figure 4) is linked with both transcriptional repression and activation depending on the residue being methylated and the extent of methylation. Both arginine residues can be methylated. Methylation occurs by histone methyltransferases (HMTs). It uses Sadenosylmethionine (SAM) as a co substrate [39].

c) Many other modifications of histone tails include phosphorylation (Figure 4), ubiquitination, sumoylation and ADP ribosylation etc [36]. 


\section{Cell \& Cellular Life Sciences Journal}

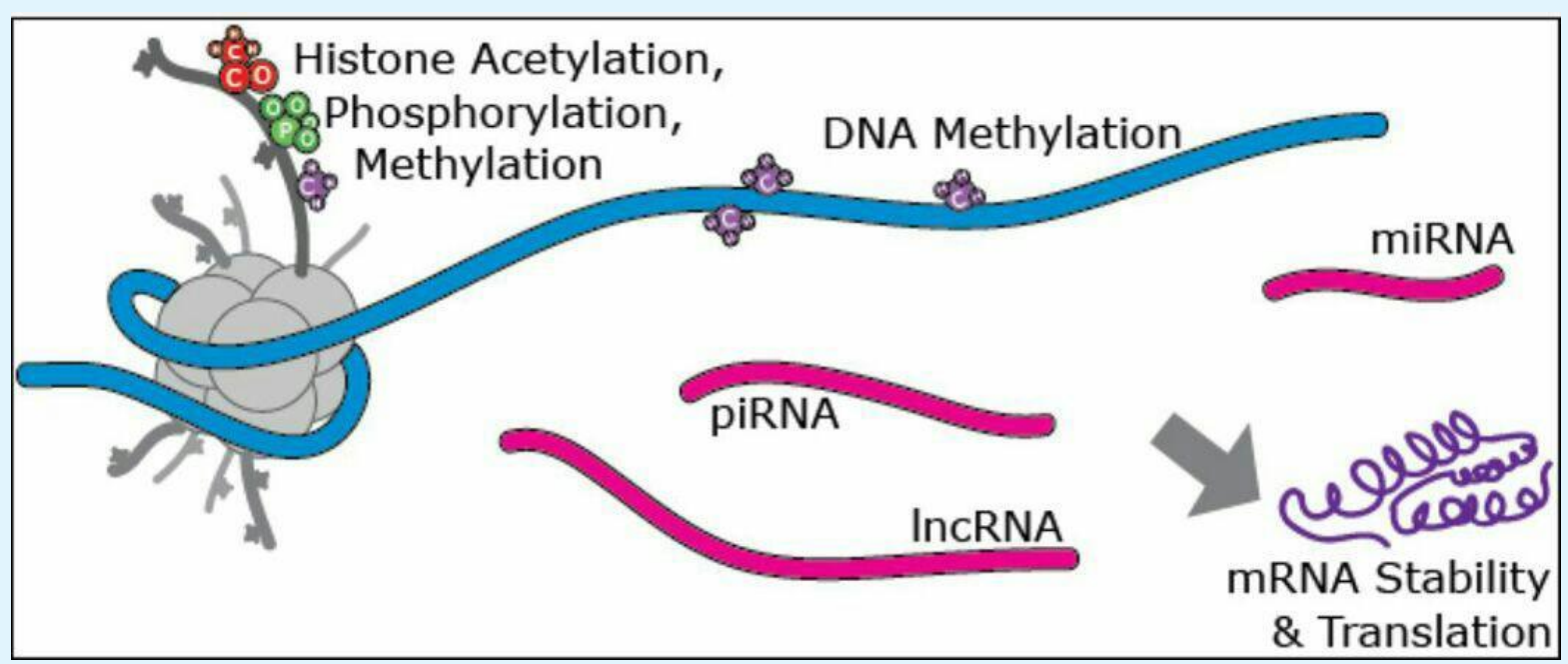

Figure 4: Molecular epigenetic modifications. Histone modifications like acetylation, methylation, phosphorylation etc and the non-coding RNA and the DNA itself convey the epigenetic information and coordination between DNA and transcription and chromatin modification machinery (Adapted from Griffiths, et al.) [40,8].

\section{Non Coding RNAs}

Many types of ncRNAs are well known, such as ribosomal (rRNA) and transfer (tRNA) RNA, IncRNAs and various short varieties, including micro (miRNA), small nuclear (snoRNA), promoter associated small RNAs (PASR), Piwiinteracting RNA (piRNA), and transcription initiation (tiRNA) types [36].

\section{Antidepressants}

The use of antidepressant drugs used till date are generally increasing the level of stress response hormones such as cortisol, norepinephrine, adrenocorticotropic hormone, endorphins etc. thus leading to relieve from stress.
However many associated drawbacks have been seen related to antidepressant action:

1. They work in too few people i.e. response rates within 6-8weeks are around $70 \%$ while resubmission rates are sometimes considerably lower.

2. It takes too long until the work i.e. the patients have to wait sometimes more than 2 months, until they get markedly better.

3. Despite substantial improvement among new antidepressants, they still have too many side effects like tiredness, restlessness, sexual dysfunction, weight gain and in some cases even aggressiveness [41].

The effects of the epigenetic modifications of FosB and Delta FosB, are summarized in table 1.

\begin{tabular}{|c|c|c|}
\hline Epigenetic modifications & FosB & DeltaFosB \\
\hline Histone 3 (H3) Acetylation & Lysine 14 acetylation & - \\
\hline Effects & $\begin{array}{c}\text { Modulate drug and stress evoked behavior and gene } \\
\text { expression [42]. }\end{array}$ & - \\
\hline Methylation & H3K9me2 & Lysine 9 methylation \\
\hline Effects & $\begin{array}{l}\text { H3K9me2 enrichment at FosB is suppressed in } \\
\text { the NAc by repeated cocaine dose and it also } \\
\text { increased at FosB in the NAc of depressed humans. } \\
\text { Local overexpression or knockdown of G9a in NAc } \\
\text { potently controls drug } \\
\text { and stress responses in rodent [43]. }\end{array}$ & $\begin{array}{l}\text { The role of histone methylation } \\
\text { changes at c-Fos and Egr-1 } \\
\text { immediate-early genes } \\
\text { (IEGs) is still unclear [42]. }\end{array}$ \\
\hline
\end{tabular}

Table 1: Effects of epigenetic modifications of Fos B and Delta Fos B. 


\section{Cell \& Cellular Life Sciences Journal}

\section{Conclusion and Future Directions}

The epigenetic factors responsible for stress are governed by $\Delta$ FosB expression level. The expression of $\Delta$ FosB in turn depends on the presence of SRF transcription factor. SRF transcription factor is encoded by srf gene. On knocking out the srf gene, $\Delta$ FosB would not get formed thus epigenetic cause of stress can be eliminated. Moreover the epigenetic modification i.e. H3K9me2 can be altered back to H3S10p-K14ac epigenetic modification [8].This epigenetic-editing approach, with assessments of physiological changes in gene expression, uncovers clear differences in the stressinduced phenotypes by Fosb gene manipulation. Such targets may be used to help initiative to develop antidepressant drug in future years. Ultimately, studies of $\Delta$ FosB elucidate the ways in which it is possible to elaborate detailed transcriptional mechanisms of stress and anti-stress action. Recent study demonstrated a molecular mechanism by which epileptic form activity might contribute to cognitive deficits in Alzheimer's disease and epilepsy. This mechanism highlights seizureinduced $\Delta$ FosB as a transcription factor that critically regulates hippocampal memory [2]. We propose that through the use of CRISPR-Cas9 technology, N-terminal of $\Delta$ FosB in human can be modified. The novel mechanistic understanding may provide new insight into improved treatments of stress.

\section{Acknowledgment}

Authors are thankful to the Principal, Gargi College for providing the infrastructural support.

\section{References}

1. Shonkoff JP, Boyce WT, McEwen BS (2009) Neuroscience, molecular biology, and the childhood roots of health disparities. JAMA 301(21): 2252-2259.

2. Matosin N, Cruceanu C, Binder EB (2017) Preclinical and clinical evidence of DNA methylation changes in response to trauma and chronic stress. Chronic stress 1.

3. Krishnan V, Han MH, Graham DL, Berton O, Renthal W, et al. (2007) Molecular adaptations underlying susceptibility and resistance to social defeat in brain reward regions. Cell 131(2): 391-404.
4. Feder A, Nestler EJ, Charney DS (2009) Psychobiology and molecular genetics of resilience. Nat Rev Neurosci 10(6): 446-457.

5. McEwen BS (1998) Protective and Damaging Effects of Stress Mediators. N Engl J Med 338(3): 171-179.

6. Chrousos GP (2009) Stress and disorders of the stress system. Nat Rev Endocrinol 5(7): 374-381.

7. Shin LM, Liberzon I (2009) The neurocircuitry of fear, stress, and anxiety disorders. Neuropsychopharmacology 35(1): 169-191.

8. McEwen BS, Bowles NP, Gray JD, Hill MN, Hunter RG, et al. (2015) Mechanisms of stress in the brain. Nat Neurosci 18(10): 1353-1363.

9. McEwen BS, Wingfield JC (2003) The concept of allostasis in biology and biomedicine. Horm Behav 43(1): 2-15.

10. McEwen BS (2006) Protective and damaging effects of stress mediators: central role of the brain. Dialogues Clin Neurosci 8(4): 367-381.

11. Govindarajan A, Rao BS, Nair D, Trinh M, Mawjee N, et al. (2006) Transgenic brain-derived neurotrophic factor expression causes both anxiogenic and antidepressant effects. Proc Natl Acad Sci USA 103(35): 13208-13213.

12. Lakshminarasimhan $H$, Chattarji S (2012) Stress leads to contrasting effects on the levels of brain derived neurotrophic factor in the hippocampus and amygdala. PLoS One 7(1): e30481.

13. Pawlak R, Rao BS, Melchor JP, Chattarji S, McEwen B, et al. (2005) Tissue plasminogen activator and plasminogen mediate stress-induced decline of neuronal and cognitive functions in the mouse hippocampus. Proc Natl Acad Sci USA 102(50): 18201-18206.

14. Chen Y, Fenoglio KA, Dube CM, Grigoriadis DE, Baram TZ (2006) Cellular and molecular mechanisms of hippocampal activation by acute stress are agedependent. Mol Psychiat 11(11): 992-1002.

15. Yan XX, Toth Z, Schultz L, Ribak CE, Baram TZ (1998) Corticotropin-releasing hormone (CRH)-containing neurons in the immature rat hippocampal formation: Light and electron microscopic features and 


\section{Cell \& Cellular Life Sciences Journal}

colocalization with glutamate decarboxylase and parvalbumin. Hippocampus 8(3): 231-243.

16. Mucha M, Skrzypiec AE, Schiavon E, Attwood BK, Kucerova E, et al. (2011) Lipocalin-2 controls neuronal excitability and anxiety by regulating dendritic spine formation and maturation. Proc Natl Acad Sci USA 108(45): 18436-18441.

17. Skrzypiec AE, Shah RS, Schiavon E, Baker E, Skene N, et al. (2013) Stress-induced lipocalin-2 controls dendritic spine formation and neuronal activity in the amygdala. PLoS One 8: e61046.

18. Hill MN, McEwen BS (2010) Involvement of the endocannabinoid system in the neurobehavioural effects of stress and glucocorticoids. Prog Neuropsychopharmacol Biol Psychiatry 34(5): 791797.

19. Gunduz Cinar O, Hill MN, McEwen BS, Holmes A (2013) Amygdala FAAH and anandamide: mediating protection and recovery from stress. Trends in pharmacological sciences 34(11): 637-644.

20. Hill MN, Kumar SA, Filipski SB, Iverson M, Stuhr KL, et al. (2013) Disruption of fatty acid amide hydrolase activity prevents the effects of chronic stress on anxiety and amygdalar microstructure. Mol Psychiatry 18(10): 1125-1135.

21. Meaney MJ, Szyf M (2005) Environmental programming of stress responses through DNA methylation: life at the interface between a dynamic environment and a fixed genome. Dialogues Clin Neurosci 7(2): 103-123.

22. Hunter RG, Gagnidze K, McEwen BS, Pfaff DW (2014) Stress and the dynamic genome: Steroids, epigenetics, and the transposome. Proc Natl Acad Sci USA 112(22): 6828-6833.

23. De Kloet ER, Fitzsimons CP, Datson NA, Meijer OC, Vreugdenhil E (2009) Glucocorticoid signaling and stress-related limbic susceptibility pathway: about receptors, transcription machinery and microRNA. Brain Res 1293: 129-141.

24. Tsankova NM, Berton O, Renthal W, Kumar A, Neve RL, et al. (2006) Sustained hippocampal chromatin regulation in a mouse model of depression and antidepressant action. Nat Neurosci 9(4): 519-525.
25. Reul JM, Chandramohan Y (2007) Epigenetic mechanisms in stress-related memory formation. Psychoneuroendocrinology 32 supply: S21-S25.

26. Heller EA, Cates HM, Peña CJ, Sun H, Shao N, et al. (2014) Locus-specific epigenetic remodeling controls addiction- and depression-related behaviors. Nat Neurosci 17(12): 1720-1727.

27. Vialou V, Robison AJ, LaPlant QC, Covington HE III, Dietz DM, et al. (2010) $\Delta$ FosB in brain reward circuits mediates resilience to stress and antidepressant responses. Nature Neurosci 13(6): 745-752.

28. Corbett BF, You JC, Zhang X, Pyfer MS, Tosi U, et al. (2017) $\Delta$ FosB Regulates Gene Expression and Cognitive Dysfunction in a Mouse Model of Alzheimer's Disease. Cell Rep 20(2): 344-355.

29. Nestler EJ (2008) Transcriptional mechanisms of addiction: role of deltaFosB. Philos Trans $\mathrm{R}$ Soc London B Biol Sci 363(1507): 3245-3255.

30. De Pauli RF, Coelhoso CC, Tesone Coelho C, Linardic A, Mello LE, et al. (2014) Withdrawal induces distinct patterns of FosB/ $\Delta$ FosB expression in outbred Swiss mice classified as susceptible and resistant to ethanol-induced locomotor sensitization. Pharmacology Biochemistry and Behavior 117: 7078.

31. Nestler EJ (2015) $\Delta$ FosB: a transcriptional regulator of stress and antidepressant responses. Eur J Pharmacol 753: 66-72.

32. Klug WS, Cummings MR, Spencer CA, Palladino MA (2016) Concept of Genetics, 11 $1^{\text {th }}$ (Edn.), Pearson pp: 708(891).

33. Newell Price J, Clark AJ, King P (2000) DNA methylation and silencing of gene expression. Trends Endocrinol Metab 11(4): 142-148.

34. Weber M, Schubeler D (2007) Genomic patterns of DNA methylation: targets and function of an epigenetic mark. Curr Opin Cell Biol 19(3): 273-280.

35. Hervouet E, Vallette FM, Cartron PF (2009) Dnmt3/transcription factor interactions as crucial players in targeted DNA methylation. Epigenetics 4(7): 487-499.

36. Vialou V, Feng J, Robison AJ, Nestler EJ (2013) Epigenetic mechanisms of depression and 


\section{Cell \& Cellular Life Sciences Journal}

antidepressants action. Annu Rev Pharmacol Toxicol 53: 59-87.

37. Borrelli E, Nestler EJ, Allis CD, Sassone Corsi P (2008) Decoding the epigenetic language of neuronal plasticity. Neuron 60(6): 961-974.

38. Cheung P, Allis CD, Sassone Corsi P (2000) Signaling to chromatin through histone modifications. Cell 103(2): 263-271.

39. Rice JC, Allis CD (2001) Histone methylation versus histone acetylation: new insights into epigenetic regulation. Curr Opin Cell Biol 13(3): 263-273

40. Griffiths BB, Hunter RG (2014) Neuroepigenetics of stress. Neuroscience 275: 420-435.

41. Tang TZ, DeRubeis RJ, Hollon SD, Amsterdam J, Shelton R, et al. (2009) Personality change during depression treatment: a placebo-controlled trial. Arch Gen Psychiatry 66(12): 1322-1330.
42. Saunderson, Spiers H, Mifsud KR, Gutierrez-Mecinas M, Trollope AF, et al. (2016) Stress-induced gene expression and behavior are controlled by DNA methylation and methyl donor availability in the dentate gyrus. Proc Natl AcadSci U S A 113(17): 48304835.

43. Maze I, Covington III HE, Dietz DM, LaPlant Q, Renthal W, et al. (2010) Essential role of the histone methyltransferase G9a in cocaine-induced plasticity. Science 327(5962): 213-216.

44. Hunter RG, McEwen BS (2013) Stress and anxiety across the lifespan: structural plasticity and epigenetic regulation. Epigenomics 5(2): 177-194.

45. Stankiewicz AM, Swiergiel AH, Lisowski P (2013) Epigenetics of stress adaptations in the brain. Science Direct 98: 76-92.

46. Reul JM (2014) Making memories of stressful events: a journey along epigenetic, gene transcription, and signaling pathways. Front psychiatry 5: 5. 